UDC: 821.134.2.09 Goytisolo J. DOI: https://doi.org/10.18485/hispserb.2019.2.ch17

\author{
Jelica Veljović ${ }^{1}$ \\ Universidad de Kragujevac \\ Serbia
}

\title{
EL NOMADISMO EN LA POÉTICA LITERARIA DE JUAN GOYTISOLO: EL CASO DE ÁLVARO MENDIOLA
}

\begin{abstract}
Resumen
Este trabajo parte de la hipótesis de que las novelas de Juan Goytisolo muestran una tendencia a reflejar los conceptos filosóficos postmodernos, en cuanto a la concepción del sujeto contemporáneo. El objetivo del presente trabajo será mostrar de qué modo se puede analizar uno de los protagonistas de Juan Goytisolo dentro del contexto de la filosofía del nomadismo. El análisis se apoyará en los conceptos de nomadismo desarrollados por Gilles Deleuze y Rosi Braidotti. Dichos conceptos se aplicarán en el desarrollo novelesco de Álvaro Mendiola, el protagonista de Trilogía de Álvaro Mendiola de Juan Goytisolo. Siguiendo los continuos cambios identitarios de dicho protagonista dentro de las tres novelas de la trilogía, se intentará concluir que Goytisolo logró presentar el sujeto de la sociedad contemporánea como un sujeto nómada.

Palabras clave: Juan Goytisolo, sujeto, postmodernismo, nomadismo, sujeto nómada.

No, no soy de los vuestros, soy el exterior y el desterritorializado, "soy de raza inferior desde toda la eternidad... soy una bestia, un negro". (Deleuze \& Guattari 1985: 111)

Estoy definitivamente al otro lado, / con los parias de siempre, / afilando el cuchillo. (Goytisolo 2012: 784)

$\overline{{ }^{1} \text { jelica.veljovic@filum.kg.ac.rs }}$
\end{abstract}




\section{Juan Goytisolo: ¿una obra y vida posmoderna y nómada?}

Al investigar diferentes aspectos de la vida y obra de Juan Goytisolo, muchos críticos y teóricos de su obra literaria recalcaron que se trata de un escritor de índole postmodernista, aunque el mismo Goytisolo lo hubiera negado criticando a los postmodernistas por su aparente intelectualidad y complicidad con el sistema capitalista global ${ }^{2}$ (Goytisolo 1999: 70-78). Sin embargo, no se puede omitir que el inicio de su fase de escritura madura, que comienza con la publicación de la novela Señas de identidad en 1966 (Sanz Villanueva 2010: 238-240), coincide con el desarrollo del período postmodernista. Además, en este período Goytisolo se dedica fervorosamente al tema de la identidad: de la búsqueda, pérdida o duda en la identidad como concepto en sí, por lo que podría confirmarse que la obra madura de Goytisolo es en parte postmodernista, como subrayaron Adriaensen (2006: 184) y Black (2001: 201). Gonzalo Navajas (1979: 163168) y Stanley Black (2001: 204) incluso enumeran una serie de rasgos de la narrativa de Goytisolo, de los que se puede decir que son comunes para la mayoría de autores postmodernistas, como por ejemplo la fragmentación, renovación estilística, pluralismo de voces narrativas, referencialidad a la historia y su desmitificación, introducción de elementos autobiográficos y el uso de la técnica de pastiche. A estas conclusiones habría que añadir que Goytisolo continuamente investigaba lo propio a través de lo extraño y lejano, llegando a deshacer las viejas jerarquías, diferencias y divisiones, creando un espacio narrativo postmodernista de fronteras líquidas ${ }^{3}$, tanto en la percepción del espacio físico como en la percepción del sujeto humano. Así es como confirmó el concepto de la otredad y la posición del Otro como constitutiva para la formación de un individuo, de su personalidad y sus rasgos identitarios, lo que llegaría a constituir un aspecto clave para la comprensión de la poética de Goytisolo (Veljovic 2014: 209). Autores como Beilin (2007: 263) incluso destacaron que fue precisamente Goytisolo el autor clave para el desarrollo del tema de la otredad en España desde la perspectiva filosófica del posestructuralismo y postmodernismo.

El proceso de análisis de la identidad del sujeto contemporáneo y reconocimiento de una identidad constituida por la multitud de otros y a través del paso a la otredad ideológica, histórica, lingüística y

\footnotetext{
${ }^{2}$ Ver más sobre este tema en su ensayo Escritores sin mandato, en la colección Cogitus interruptus de Goytisolo. El ensayo fue publicado primero en el año 1997 como un artículo en el periódico El país con el mismo nombre.

${ }^{3}$ La noción de la liquidad es utilizado aquí en el sentido postmodernista, tal y como lo introdujo el teórico Zygmunt Bauman en la teoría del postmodernismo, creando inicialmente la metáfora "liquid modernity" (la modernidad líquida).
} 
cultural, comienza precisamente con el desarrollo de Álvaro Mendiola: el protagonista de las tres novelas de Trilogía de Álvaro Mendiola, cuyo comienzo es marcado con el año 1966 cuando se publicó la novela Señas de identidad. El protagonista de esta novela, y de las dos siguientes de la trilogía, es un exiliado español cuyo desarraigo con la patria España comienza después de la Guerra civil española (1936-1939) y durante la época del franquismo. Habría que señalar que el mismo proceso del desarraigo identitario lo sufrió Juan Goytisolo, y que en efecto creó a Mendiola como su alter ego, o mejor dicho, como un héroe autoficticio que le pueda ayudar al autor buscar las señas de su identidad para luego desposeerse de ella. Esta frontera nebulosa entre el autor y el protagonista la destacó Gould Levine (2006: 30-31) y la confirman hechos de que el héroe y su autor comparten la infancia trágica en España, el exilio en Francia y la apertura tanto hacia la diversidad cultural del mundo dentro y fuera de la Patria como dentro de sí mismo. Precisamente la partida de España y el exilio voluntario del autor tuvieron un impacto clave a su formación artística e ideológica, como él mismo destacó: "para mí el exilio, a partir de un determinado momento, no ha sido un lamento sino que ha sido una fuerza vital cuyo impulso se ha prolongado después de que desapareció la razón que lo provocó" (Goytisolo 1991: 40). Así es como llegó a autodefinirse a sí mismo como "el escritor entre fronteras" (Goytisolo 2004: 8) y como un "Cervantino"4 en cuanto a la nacionalidad, ofreciendo de este modo en su obra una perspectiva transnacional y culturalmente diversa. Por las mismas razones se destaca que para Goytisolo la literatura es un hecho migratorio (Adriaensen 2009: 270), de lo que podría entenderse que él fue un nómada a través de diferentes espacios, épocas y culturas. Además de su propia vida y de la vida de su protagonista autoficticio, también su estilo es marcado como "una larga trayectoria de la escisión interior" (Meerts 1982: 111) y como un "nomadismo discontinuo de la palabra" (Carrera 1991: 37).

\section{La filosofía del nomadismo: la interrogación de la identidad}

El tema de la otredad es imprescindible en cuanto a las teorías filosóficas, sociológicas, antropológicas y culturales sobre el sujeto

\footnotetext{
${ }^{4}$ Goytisolo había pronunciado en una entrevista concedida a Iñaki Gabilondo en el programa Hoy el 26 de octubre de 2010 (la televisión CNN+ España) que cada definición nacional le pone nervioso, por lo que podía declararse como un Cervantino si tenía que hacerlo: "Si me defino de nacionalidad, digo que mi nacionalidad es Cervantina".

La entrevista está disponible en el siguiente enlace:

https://www.youtube.com/watch?v=00si49Anmis
} 
contemporáneo y las identidades marcadas por los grandes cambios históricos del siglo XX. Todos los paradigmas de ciencias sociales y de humanidades están evidentemente marcados por la afirmación de la otredad, que según los autores más destacados, como Emmanuel Levinas, Jacques Derrida o Gil Deleuze, está inscrita en la formación de la identidad misma. La comprensión de la otredad como constitutiva de la identidad abrió la mirada hacia un horizonte nuevo del Ser, que se constituye únicamente a través de la dislocación del centro, o sea, la descentralización en cuanto a su identificación primordial, que hasta ese momento fue definido como la razón, la conciencia o el cogito. Habría que destacar que esta afirmación de la otredad ha comenzado con el psicoanálisis de Jacques Lacan y luego con la gramatología de Jacques Derrida, que afirmaron (cada uno por sí mismo) que el concepto clave es la diferencia que está en el centro del sujeto, lo que le permite al sujeto una variación continua de la identidad, unos juegos identitarios y una multiplicación de los niveles que le forman y le dan únicamente la impresión de la identidad. Asimismo Derrida (1981: 326) concluyó que el Yo del sujeto racional es en efecto siempre desalojado y reubicado, o sea, diseminado, siempre en movimiento identitario. Siguiendo estas pautas surgen tantas preguntas en cuanto a la identidad misma que puede confirmarse que los autores como Juan Goytisolo ponen delante de sus lectores una de las mayores preguntas y quizá una de las mayores aporías de nuestro tiempo: ¿existe la identidad?

Las categorías metafóricas aquí mencionadas de la filosofía posmodernista - el otro, la diferencia, la diseminación - pusieron un signo de interrogación ante el concepto de la identidad, despertando una serie de asociaciones con el nomadismo al que el sujeto contemporáneo está expuesto. Precisamente desde estos puntos parten los primeros principios de la filosofía del nomadismo introducido por Gilles Deleuze. Deleuze (Delez 2009: 102) comienza con la noción de la diferencia diciendo que cada sujeto humano debería observar cómo su identidad se hunde y desaparece ante la diferencia, y que al final el Yo de cada sujeto está formado por las diferencias. Luego medita cómo esto influye en el movimiento inevitable y en el desraizamiento universal del ser humano, apoyándose en los textos posmodernistas sobre el exilio, vagabundeos y migraciones como hechos universales de la época contemporánea. $\mathrm{Al}$ hacerlo, Deleuze se da cuenta de la fluidez de la identidad y de sus continuos trastornos, introduciendo el concepto de la esquizofrenia en la comprensión filosófica del sujeto contemporáneo. Este sujeto esquizofrénico, diseminado, fluido e intersectado por las diferencias internas, es incapaz de decir "Yo" en primera persona singular: 
Tal vez se diga que el esquizo no puede decir yo, y que es preciso devolverle esta función sagrada de enunciación. Ante lo cual dice resumiendo: se me vuelve a enmarañar. "Ya no diré yo, nunca más lo diré, es demasiado estúpido. Pondré en su lugar, cada vez que lo oiga, a la tercera persona, si pienso en ello. Quizás esto les divierta, sin embargo, no cambiará nada." Y si vuelve a decir yo, esto tampoco cambiará nada. (Deleuze \& Guattari 1985: 30-31)

Estos postulados de la obra deleuziana fueron unos impulsos para que la identidad y el sujeto se representen con imágenes metafóricas primero del rizoma y luego del nómada. El nómada deleuziano está vinculado con la filosofía del sujeto esquizofreno por ser "transposicional" (Deleuze \& Guattari 1985: 95) con lo que se indica su inestabilidad identitaria. Además de este, se pueden demarcar los siguientes rasgos e ideas relacionados con el sujeto nómada: el nómada es un viajero y cazador contemporáneo que huye de los flujos de la codificación social oficial; no pertenece a un lugar o espacio físico preciso; se desposeyó de un centro identitario que lo definiera; no se incorpora a la jerarquía social; vive en un exilio continuo y en los espacios desiertos por el hecho de desterritorializarse continuamente (Deleuze \& Guattari 1985: 154-155). En su interpretación del concepto del nómada deleuziano, Colebrook (2005: 182) recalca que el nomadismo supone una liberación del pensamiento de un principio exterior y transcendental, como es logos. De este modo parece significativo subrayar que el nomadismo deleuziano supone una ruptura con la filosofía del racionalismo y de la ilustración.

El concepto del sujeto nómada luego fue ampliado por Rosi Braidotti, alumna de Deleuze, que encuentra en este concepto una posibilidad de renovación y evolución del sujeto humano. En su obra Nomadic Subjects. Embodiment and Sexual Difference in Contemporary Feminist Theory Braidotti resalta que el nómada es el portador de la diversidad cultural, porque se basa en el principio del movimiento e implica una existencia basada en la heterogeneidad. Asimismo aplica las expresiones metafóricas como el mapa o el inventario de las huellas dejadas, para describir el hibridismo de la existencia nómada:

La identidad del nómada es el mapa de los lugares en los que él / ella ha estado; él / ella siempre puede reconstruirlo posteriormente como una secuencia de los pasos en un itinerario. Sin embargo, no existe un cogito vigilando a la contingencia del ser; el nómada representa una diversidad en movimiento, y la identidad del nómada es un inventario de huellas 5 . (Braidotti 1994: 14)

\footnotetext{
${ }^{5}$ La traducción pertenece a la autora del artículo. La cita original está en inglés: "The
} 
Es interesante que Braidotti destaque también el aspecto lingüístico de la existencia nómada. Según esta ampliación del concepto mismo, el nómada tiene una conciencia crítica siendo capaz de conducir de un escepticismo saludable, gracias al estar entre lenguas y diversos espacios lingüísticos a la vez. Esto significa para Braidotti (1994: 15) que el nómada es un políglota, que no solamente entiende varias lenguas, sino que incluso es políglota en su propia lengua por renovar, deconstruir y liberarla de los significados ideológicos y osificados. Podría concluirse que precisamente en esto reside también la estética nómada, dentro de la que el mayor tema es la liberación de la estabilidad ilusoria de la identidad y la aseveración de las voces de los otros: subyugados y marginados (Braidotti 1994: 36-38). Ambos temas destacados como representantes de una estética nómada pueden relacionarse con la literatura del exilio y de los trastornos identitarios que sufren sus protagonistas como es el caso de Álvaro Mendiola de Juan Goytisolo.

Al resumir los puntos teóricos más básicos para la comprensión de la filosofía del nomadismo, puede suponerse que el escritor Juan Goytisolo cubrió la mayoría de los aspectos de la filosofía nómada tanto por haber llevado una vida del exiliado y apátrida y por ofrecer una perspectiva transnacional como por crear un protagonista como Álvaro Mendiola, que primero va en pos de su identidad, para comenzar luego un largo proceso de desposeerse de esta identidad primaria y de optar solo por una libertad identitaria más amplia. Precisamente esta libertad identitaria más amplia podría definirse como la libertad de un nómada, tal y como el protagonista expresa al final de la Trilogía de Álvaro Mendiola.

\section{Presagios del nomadismo en novelas Señas de identidad y Conde don Julián}

Analizando la Trilogía de Álvaro Mendiola desde el aspecto de la transformación de la identidad del protagonista que paulatinamente salta de los moldes identitarios conocidos, puede suponerse que en la primera novela de la trilogía, Señas de identidad, Goytisolo estableció la primera etapa del camino del desarraigo identitario, marcando a Álvaro Mendiola como un exiliado español. Cornago Bernal (2002: 100) señaló que era el exilio de Álvaro Mendiola que sirvió como el punto clave para su alienación

nomad's identity is a map of where s/he has already been; $\mathrm{s} /$ he can always reconstruct it a posteriori, as a set of steps in an itinerary. But there is no triumphant cogito supervising the contingency of the self; the nomad stands for movable diversity, the nomad's identity is an inventory of traces." 
y desviación, lo que para el autor "actuará como el motor esquizoide de su narrativa”. Esta línea esquizoide de la narrativa de Goytisolo o de la ruptura identitaria de su personaje autoficticio continúa en la siguiente novela, Conde don Julián, en la que el exilio motiva el deseo de Mendiola de desarraigarse a través de la desmitificación y la deconstrucción de España.

Puede señalarse que el tema de la primera novela de la trilogía es la búsqueda de los elementos constitutivos básicos de un exiliado en Francia, proveniente de una familia burguesa bien acomodada en Barcelona. Al dejar su patria, Álvaro Mendiola comenzó un largo rumbo de investigación de la identidad tanto de sí mismo como de España entera desde una perspectiva diacrónica. Por sentirse alienado de su patria, su familia y su pueblo, presentes como los primeros horizontes identitarios, Álvaro siente una desintegración y desorientación interior que intenta sobrepasar con la vuelta a España. Sin embargo, la reintegración en el lugar primordial de su identificación resultó ser un paso más hacia la alienación y pérdida de señas de identidad, puesto que Álvaro descubrió que nunca la tenía fija y estable. Así la búsqueda de la identidad que forma el primer estrato temático de la novela resulta ser ilusoria, revelando la imposibilidad de constitución de la misma. Comportándose como un "peregrino modernista" por su necesidad de restaurarse a sí mismo para salir de la inestabilidad (Bauman 2001: 114), nostálgico y deseoso de fortalecer los lazos que le unen con el lugar de proveniencia, Álvaro llega a confirmar la imposibilidad del retorno de un exiliado y la discontinuidad identitaria y existencial del exilio. Asimismo llegó a descubrir que siempre se identificaba más con la parte marginada de su familia, como su tío Néstor, o los marginados sociales y políticos, como el revolucionario Jerónimo trabajando de jornalero en la hacienda de la familia Mendiola. Hojeando las páginas del álbum familiar e investigando los recuerdos de su infancia, Álvaro se da cuenta de que siempre se sentía opuesto a los valores éticos e ideológicos de su familia, lo que se afirma en sus continuas reflexiones entrecruzadas con los recuerdos del pasado: "Lentamente, conforme se rompían las raíces que lo ligaban a la infancia y a la tierra, Álvaro había sentido formarse sobre su piel un duro caparazón de escamas: la conciencia de la inutilidad del exilio y, de modo simultáneo, la imposibilidad del retorno" (Goytisolo 2012: 283). La mencionada discontinuidad identitaria del protagonista se representa también con la metáfora del árbol, que quedará vigente también en otras obras de Goytisolo: 
...como si las raíces que te unieran a la tribu se hubiesen secado una tras otra como consecuencia de tu dilatada expatriación y de vuestra indiferencia recíproca. Rama amputada del tronco natal, planta crecida en el aire, expulsado como tantos otros de ahora y de siempre por los celosos guardianes de vuestro secular patrimonio. (Goytisolo 2012: 361-362)

Estas reflexiones de Álvaro sobre su extrañamiento de la familia y de la patria pueden considerarse como los primeros indicios de la creación del sujeto nómada, que va a acentuarse conforme al crecimiento de su desorientación identitaria y el paso de varias fronteras y espacios nacionales.

Después de sentirse alienado también de los españoles exiliados en Francia, Álvaro emprenderá varios viajes a través de Europa, sintiéndose cada vez más alejado de su deseo de integración pero intensificando todavía la necesidad de reencontrarse en algún sitio nuevo o en las personas que le rodean. Esto se denota durante su estancia en Cuba, al asistir a una ceremonia iniciática de los negros yorubas, y en la historia de su fracaso amoroso con Dolores en Ginebra. La novela entera parece ser una serie de intentos e imposibilidades de reestablecerse y reconstituirse a través de la otredad o de los otros que giran en torno a Álvaro y forman parte de su vida, mostrándole que únicamente existen rupturas y desposesiones de la identidad. Precisamente este aspecto de las búsquedas de Álvaro parece ser clave para la comprensión de este personaje como una plataforma para el desarrollo de la identidad nómada. Braidotti (1998) señala que la conciencia nómada implica la subversión y resistencia tanto hacia los modelos de existencia y pensamiento que son social e ideológicamente establecidos, como hacia las corrientes hegemónicas oficiales. El protagonista de Goytisolo nos muestra precisamente estos valores como parte inseparable de su posición de exiliado, estando al margen de la sociedad franquista y manteniendo una perspectiva crítica y rebelde hacia ella. Esto se denota en el final de la novela, cuando Álvaro mira su ciudad natal, Barcelona, desde el castillo de Montjuic, despidiéndose del país que ya no siente como parte de su ser por las diferencias políticas y éticas:

separémonos como buenos amigos puesto que aún es tiempo / nada nos une ya sino tu bella lengua mancillada hoy por sofismas mentiras hipótesis angélicas aparentes verdades (...) mejor vivir entre extranjeros que se expresan en idioma extraño para ti que en medio de paisanos que diariamente prostituyen en propio (Goytisolo 2012: 434) 
El fin de la novela representa la última despedida de Mendiola con la patria, que para él dejó de ser patria tanto física como simbólicamente, lo que anunció de algún modo a Mendiola como a un vagabundo postmodernista, marcado por la migración, que continúa en la siguiente parte de la trilogía.

En la novela Conde don Julián encontramos al protagonista de Goytisolo "definitivamente del otro lado"- en Marruecos, en Tánger, mirando a su patria a través de la tiniebla y por encima del estrecho de Gibraltar, sintiéndola metafóricamente como una madrastra y una cicatriz venenosa que, sin embargo, todavía no le permite seguir hacia adelante, despojarse de ella como su identidad primordial:

adiós, Madrastra inmunda, país de siervos y señores: adiós, tricornios de charol: adiós, pueblo que los soportas: quizás yo tras el mar del Estrecho esconderme podré de tus tiranos: (...) comprobando una vez más, con resignación quieta, que la invectiva no te desahoga: que la Madrastra sigue allí, agazapada, inmóvil... (Goytisolo 2012: 450)

Marcado por el deseo de liberarse finalmente de las señas de la identidad anterior, Álvaro fantasea con ser el mítico traidor de la España cristiana y visigoda del siglo VI - el conde Don Julián. Puede considerarse que este deseo de traicionar la Patria y de cumplir el papel de un antiguo y mitificado enemigo en la historia de los godos españoles, que formaron una parte importante en la ideología nacional franquista después de la Guerra civil, muestra la resistencia nómada (Braidotti 1998) hacia la hegemonía oficial de España franquista, actual de ese momento. Habría que señalar que la traición nómada sobre la que fantasea Mendiola se iguala con la liberación identitaria, tan deseada: "placer de la traición: de liberarse de aquello que nos identifica, que nos define: que nos convierte, sin quererlo, en portavoces de algo que nos da etiqueta y nos fabrica una máscara:..." (Goytisolo 2012: 540). Analizando esta introspección del protagonista, puede concluirse que Mendiola muestra el deseo de desposeerse del centro que había modelado su identidad, que es otro de los rasgos del sujeto nómada (Deleuze \& Guattari 1985: 154). Para llevar a cabo esta desposesión y la subversión de la Patria oficial, la novela Conde don Julián está completamente constituida de las fantasmagorías de Mendiola en las que este lleva a cabo la desmitificación de una serie de elementos históricos, étnicos, geográficos, religiosos, lingüísticos y literarios españoles de la ideología nacional católica aplicando técnicas narrativas como pastiche y parodia, y los principios de la lectura deconstruccionista derridiana. 
La novela trata también el tema del conflicto interior del protagonista, que se ve escindido por el trauma de la pérdida de un lugar seguro de la formación (hogar) por un lado, y por el deseo de liberarse de la identidad antigua y de formarse de nuevo de otro lado. Su conciencia contrapuntual $^{6}$ de exiliado se nota tanto en el nivel del léxico, como en el nivel de la sintaxis y de la forma de la novela, que siguen el flujo de su subconsciencia: de sus delirios y deseos más profundos. Gould Levine (1976: 95,111) destacó que Mendiola está dividido en dos lados opuestos y hasta enemigos entre sí: en el Yo pasado, representado por el fantasma del niño Álvaro que persigue a Álvaro exiliado por las calles de Tánger, y en Álvaro que desea ser Don Julián y desmitifica el sistema tradicional español. Aunque el protagonista parece traumatizado por esta fragmentación y diseminación identitaria, él busca sobrepasarla luchándo contra sí mismo, o sea, contra su antiguo Yo. Esto sucede en una serie de fantasmagorías violentas de Mendiola, en las que Álvaro-Don Julián tortura y envenena a su antiguo Yo, o sea, el niño Álvaro, hasta pervertir y degenerar por completo el último recuerdo. El acto de la autodestrucción es, aunque ficticio, una señal valiosa del deseo nómada de desposesión identitaria total de Álvaro.

Sin embargo, sus esfuerzos de liberarse de la identidad como de un peso, o de olvidarla como a una vieja cicatriz, permanecen en esta novela solo en el dominio de su deseo e imaginación, interiorizados e imposibles. Asimismo, al final de la novela encontramos al protagonista en su habitación con una mirada todavía para España: "para la costa enemiga, para la venenosa cicatriz que se extiende al otro lado del mar..." (Goytisolo 2012: 619), anunciando la continuación de su deseo nómada de liberarse y huir de las antiguas señas de identidad. Por lo tanto, Álvaro muestra al final una clara tendencia hacia el nomadismo concluyendo que: "...la patria no es la tierra, el hombre no es el árbol: ayúdame a vivir sin suelo y sin raíces: móvil, móvil..." (Goytisolo 2012: 532). Y esta tendencia será más clara y desarrollada en la última novela de la trilogía, en la que el protagonista se queda encerrado en sus vacilaciones, reflexiones e imágenes fantasmagóricas... pero que obtiene la liberación deseada y la identidad de un nómada, implicada en el título.

\footnotetext{
${ }^{6}$ El término está empleado aquí según la teoría de Edward Said sobre las especificidades de la existencia de los exiliados. Véase: E. W. Said, Reflections on Exile and Other Essays, Cambridge: Harvard University Press, 2000.
} 


\section{La liberación nómada de la identidad en Juan sin Tierra}

Comentando la última novela de su Trilogía de Álvaro Mendiola en una entrevista con Julio Ortega, Goytisolo (1977: 290) declaró que al final otorgó a Mendiola la libertad de un hombre que no tiene nada más que perder - la de un nómada. Se puede proponer que esta es la liberación primero anticipada en Señas de identidad y luego deseada y fantaseada en Conde don Julián. Además, esta declaración del autor parece muy significativa a la hora de marcar los rasgos nómadas de su protagonista que continúa con la tarea desmitificadora y deconstruccionista de Álvaro-Don Julián de la segunda parte. Por seguir con la subversión de los metarrelatos de la tradición española y de la Europa occidental, muchos críticos ya señalaron que con la última parte de la trilogía Goytisolo expresa la necesidad de emprender un viaje nómada para revelar los procesos que llevan a la fijación de la identidad, logrando crear para este fin un "discurso nómada" (Black 2001: 31). Puede señalarse que el alejamiento y el extrañamiento de un protagonista que desea ser nómada son evidentes ya al comienzo del segundo capítulo de la novela:

...el exilio te ha convertido en un ser distinto, que nada tiene que ver con el que conocieron: su ley ya no es tu ley: su fuero ya no es tu fuero: nadie te espera en Ítaca: anónimo como cualquier forastero, visitarás tu propia mansión y te ladrarán los perros:... (Goytisolo 2012: 669)

Este sentimiento apátrida de Mendiola será reforzado con la reversión simbólica de la historia colonial y actual de España, por lo que la gran parte de la novela podría definirse como una escritura metatextual de la historia española y europea revertida y descodificada, en términos deleuzianos. Asimismo, Mendiola reescribe paródicamente la historia colonial española, relacionada con el pasado colonial de su propia familia, derribando el discurso historiográfico oficial a través de una serie de bricolajes y pastiches discursivos. Paralelamente a esto, el protagonista reescribe la historia de su propio nacimiento, imaginándola en una cabaña de los esclavos negros de la encomienda de los Mendiola para "empezar el ciclo de nuevo" (Goytisolo 2012: 632). Este nuevo comienzo podría interpretarse como el indicio de la creación de la nueva identidad del protagonista, en el lado de los marginados, parias, subyugados y del otro lado del sistema logocéntrico de la Europa occidental. Esto lo muestra también la llamada de Álvaro destinada a todos los que forman la otredad de la civilización del mundo occidental, anunciando el vendaval de la destrucción de este orden antiguo: 
una a una / arrancaréis sus miserables carretas / pájaro en mano / pero sin desdeñar los cien que vuelan / los obligaréis a encuerarse también y los someteréis al escarnio cruel de vuestro vengativo discurso / oídnos bien / las trampas de vuestra razón no lograrán apresarnos / moral / religión / sociedad / patriotismo / familia / son ruidos conminatorios cuyo sonoro retintín nos dejará indiferentes / no contéis con nosotros / creemos en un mundo sin fronteras / judíos errantes / herederos de Juan sin Tierra / acamparemos allá adonde nos lleve el instinto... (Goytisolo 2012: 689)

Yendo en contra de todo lo familiar a Mendiola, en contra de todos los elementos constitutivos de su identidad, Mendiola se convierte en un "viajero contra-espacial", como afirma Carrión (2009: 27), y, por lo tanto, en un nómada, porque va conscientemente en la dirección opuesta a todo lo previsto y familiar. Incluso la llamada a hacer acampamentos y no tener lugares fijos de estancia, el modo de caminar "en contra de..." y el considerarse el heredero de Juan sin Tierra implican en este último nivel el autoconocimiento nómada y una depuración identitaria. De este modo podemos relacionar a Mendiola de nuevo con los postulados de Braidotti sobre el nómada, puesto que se opone a un monolitismo cultural, a la jerarquía logocéntrica, confirmándose solo en el movimiento, libertad y en los espacios de por medio. En la última instancia, parece que Álvaro encuentra la liberación identitaria deseada precisamente en el nomadismo.

En el final de la novela Goytisolo representa una ruptura más del protagonista, y esta es con la lengua materna, que le quedó como el último lazo a Álvaro con España. En un hilo narrativo compacto, que consiste en un solo fragmento en forma de prosa poética, en la que se solapan y paulatinamente sustituyen el castellano y el árabe, Álvaro logra despojarse de la lengua materna, para terminar la novela en árabe escrito con letras arábicas: "Los que no me entendéis, / dejad de seguirme. / Nuestra comunicación ha terminado. / Estoy definitivamente al otro lado, / con los parias de siempre, / afilando el cuchillo"7 (Goytisolo 2012: 784). Este significativo paso lingüístico del protagonista supone también el paso y el cambio identitario, confirmando de nuevo su deseo de subversión y transgresión de la identidad dada. Además de conseguir la libertad óptima de un nómada, Álvaro de la novela Juan sin Tierra parece cumplir con uno de los rasgos del sujeto nómada más, convertirse en un políglota que está entre lenguas, como lo propuso Braidotti (1994: 15). Cornago Bernal $(2002: 111,117)$ marcó este último discurso de Mendiola

\footnotetext{
${ }^{7}$ El texto citado aquí es la traducción del árabe a español tal y como aparece en el prólogo de la "Trilogía Álvaro Mendiola” del año 2012, escrito por el crítico Santos Sanz Villanueva.
} 
como "un discurso de locura", y como "una semiología poliglota"... sin embargo, podemos confirmar que se trata de un discurso nómada de un protagonista transfigurado desde un exiliado nostálgico hasta un nómada, liberado de todo lo que le une al concepto de la identidad fija y estable.

Al final, el nomadismo podría señalarse incluso como una parte de la estética literaria de Goytisolo, en la que coincide con los postulados de Braidotti sobre la denominada "estética nómada". Al comienzo de su argumentación sobre los sujetos nómadas, la autora recalca que la estética nómada implica una escritura que sea el proceso del revelamiento de estabilidad ilusoria de las identidades estables, la explosión de la burbuja da la seguridad ontológica que emana de la relación con un determinado espacio lingüístico, la liberación del significado sedentario de las palabras y una deconstrucción de los campos simbólicos establecidos como naturalizados y permanentes (Braidotti 1994: 15-17). Al seguir el desarrollo identitario de Álvaro Mendiola y su superación, en estrecha relación con la deconstrucción de metarrelatos oficiales, reversión de epistemología vigente y superación de los vínculos determinantes de la lengua materna, se puede señalar que con la Trilogía de Álvaro Mendiola, considerada en su totalidad, Goytisolo logra desarrollar una estética nómada, que fomenta la epifanía de una perspectiva transnacional y transcultural tan propia y elogiada por el autor.

\section{BIBLIOGRAFÍA}

Adriaensen, Brigitte. “Coming to Terms with Franco's Legacy: Trauma and Cultural Difference in the work of Juan Goytisolo". John Osborne et al. (Eds.). Studia Imagologica: Image into Identity. Constructing and Assigning Identity in a Culture of Modernity, Vol. 11, Amsterdam: Rodopi, 2006: 53-67. Print.

Adriaensen, Brigitte. "Juan Goytisolo en diálogo con Cervantes y Borges: un ensayo de lectura". Marco Kunz \& Brigitte Adriaensen (Eds.). Pesquisas en la obra tardía de Juan Goytisolo. Amsterdam, New York: Rodopi, 2009: 259-276. Impreso..

Bauman, Zygmunt. La posmodernidad y sus descontentos. Madrid: Akal, 2001. Impreso. 
Beilin, Katarzyna. “Ética de otredad”. R. Johnson \& J. M. del Pino (Eds.). Del infierno al cuerpo. La otredad en la narrativa y en el cine español contemporáneo, Madrid: Ediciones Libertarias, 2007: 263-294. Impreso.

Black, Stanley. Juan Goytisolo and the Politics of Contagion, Liverpool: Liverpool University Press. Print.

Braidotti, Rosi. Nomadic Subjects. Embodiment and Sexual Difference in Contemporary Feminist Theory, New York: Columbia University Press, 1994. Print.

Braidotti, Rosi, "Difference, diversity and nomadic subjectivity", 1998 <http://scholar.googleusercontent.com/scholar?q=cache:srtMlN ZFb8oJ:scholar.googl.com/+braidotti+difference+diversity+nom adic\&hl=sr\&as_sdt=0\&as_vis=1 > Web. 30 Dic. 2015.

Carrera, Arturo. "Juan Goytisolo". Manuel Ruiz Lagos (Ed.). Juan Goytisolo. Madrid: Ediciones de Cultura Hispánica, 1991: 37-39. Impreso.

Carrión, Jorge. Viaje contra espacio. Juan Goytisolo y W. G. Sebald. Madrid: Iberoamericana / Frankfurt: Vervuert, 2009. Impreso.

Colebrook, Claire. "Nomadicism". Adrian Parr. The Deleuze Dictionary. Edinburg: Edinburgh University Press, 2005: 180-183. Print.

Cornago Bernal, Óscar. "Historia de la locura en la época posmoderna: el viaje esquizoide de Juan Goytisolo". Anales de la literatura española contemporánea, 27/2 (2002): 381-416. Impreso.

Deleuze, Gil, Guattari, Felix. El Anti-Edipo: Capitalismo y esquizofrenia, Barcelona: Ediciones Paidós Ibérica, 1985. Impreso.

Delez, Žil. Razlika i ponavljanje. Beograd: Fedon, 2009. Štampano. Goytisolo, Juan. Disidencias. Barcelona: Seix Barral, 1977. Impreso.

Goytisolo, Juan. "Cronología". Manuel Ruiz Lagos (Ed.). Juan Goytisolo. Madrid: Ediciones de Cultura Hispánica, 1991: 64-65, 103-122. Impreso.

Goytisolo, Juan. Cogitus interruptus, Barcelona: Seix Barral, 1999. Impreso. Goytisolo, Juan. "Trilogía de Álvaro Mendiola”. Barcelona: RBA Libros, 2012. Impreso.

Gould Levine, Linda. Juan Goytisolo: La destrucción creadora. Mexico: Joaquín Mortiz, 1976. Impreso.

Gould Levine, Linda. "Confessions of a Goytisolo critic: Who's Reading - and Creating - Whom". Stanley Black (Ed.). Juan Goytisolo: Territories of Life and Writing. Bern: Peter Lang, European Academic Publishers, 2006: 29-40. Print. 
Meerts, Christian. "La formación del 'Yo' o el círculo". Jesús Lázaro. Juan Goytisolo: selección de críticas. Madrid: Closas-Orcoyen, 1982: 112-120. Impreso.

Navajas, Gonzalo. La novela de Juan Goytisolo, Madrid: Sociedad general española de librería S. A., 1979. Impreso.

Sanz Villanueva, Santos. La novela española durante el franquismo, Madrid: Gredos, 2010. Impreso.

Veljović, Jelica. "La constitución de la identidad marginada en la novela Señas de identidad de Juan Goytisolo". Verba Hispanica, 22 (2014): 197-212. Impreso.

\section{THE NOMADISM IN THE LITERARY POETICS OF JUAN GOYTISOLO: THE CASE OF ÁLVARO MENDIOLA}

\section{Summary}

The present paper derives from the hypothesis that the novels of Juan Goytisolo present a tendency to reflect the concepts of the postmodernist philosophy related to the conceptions of a contemporary subject. The main objective of the paper is to demonstrate how one of the protagonists of Juan Goytisolo can be analysed in the framework of the philosophy of nomadism. In order to convey this analysis, the author of the paper relies on the concepts from nomadic philosophy developed by Gilles Deleuze and Rosi Braidotti. These concepts will be applied on the literary development of Alvaro Mendiola, Goytisolo's protagonist in the famous "Trilogy of Alvaro Mendiola". Following continuous identity changes of this literary hero throughout the novels that form the trilogy, the paper will tend to draw to the conclusion that Goytisolo succeeded in the representation of a contemporary subject as a nomadic subject.

Keywords: Juan Goytisolo, subject, postmodernism, nomadism, nomadic subject. 